\title{
Improvement in long-term survival after hospital discharge but not in freedom from reoperation after the change from atrial to arterial switch for transposition of the great arteries
}

Jürgen Hörer, MD, ${ }^{\mathrm{a}}$ Christian Schreiber, MD, PhD, ${ }^{\mathrm{a}}$ Julie Cleuziou, MD, ${ }^{\mathrm{a}}$ Manfred Vogt, MD, PhD, ${ }^{\mathrm{b}}$ Zsolt Prodan, MD, Raymonde Busch, MSc, ${ }^{\mathrm{c}}$ Klaus Holper, MD, PhD, ${ }^{\mathrm{a}}$ and Rüdiger Lange, $\mathrm{MD}, \mathrm{PhD}^{\mathrm{a}}$

Objective: To compare survival, freedom from reoperation, and functional status between atrial switch and arterial switch operations for transposition of the great arteries.

Methods: Data from 88, 329, and 512 patients who underwent Mustard, Senning, and arterial switch operations between 1974 and 2006 were analyzed.

Results: In-hospital mortalities were $8.0 \%$ for Mustard, 4.6\% for Senning, and 6.4\% for arterial switch. Presence of ventricular septal defect (hazard ratio 3.3, $P<.001$ ) was the only risk factor for in-hospital mortality in multivariate analysis. Follow-up for Mustard was $22.6 \pm 8.1$ years, for Senning was $18.2 \pm 5.7$ years, and for arterial switch was $9.5 \pm 5.7$ years. Highest survival at 20 years was after arterial switch $(96.6 \% \pm 1.3 \%)$, followed by Senning $(92.6 \% \pm 1.5 \%)$ and Mustard $(82.4 \% \pm 4.3 \%)$. Transposition with ventricular septal defect (hazard ratio 3.1, $P<.001$ ), transposition with ventricular septal defect and left ventricular outflow tract obstruction (hazard ratio 3.0, $P=.029$ ), and Mustard operation (hazard ratio 2.1, $P=.011$ ) emerged as risk factors for late death, with arterial switch a protective factor (hazard ratio $0.3, P=.010$ ). Highest freedom from reoperation at 20 years was after Senning $(88.7 \% \pm 1.9 \%)$, followed by arterial switch $(75.0 \% \pm 6.4 \%)$ and Mustard $(70.6 \% \pm 5.4 \%)$. Presence of complex transposition (hazard ratio $2.1, P<.001)$, previous palliative operation (hazard ratio 1.8, $P=.016$ ), surgery between 1985 and 1995 (hazard ratio 2.6, $P=.002$ ), surgery after 1995 (hazard ratio 3.5, $P<.001$ ), and Mustard operation (hazard ratio 3.3, $P<.001$ ) emerged as risk factors for reoperation.

Conclusion: Change from atrial to arterial switch led to improved long-term survival after hospital discharge but not to lower incidence of reoperation. Survival and freedom from reoperation are determined by morphology.

Transposition of the great arteries (TGA) is the most common cyanotic heart defect in infancy and accounts for almost $10 \%$ of all cases of congenital heart disease. ${ }^{1}$ Successful therapy for TGA was first possible with the introduction of the surgical atrial septectomy in $1950 .^{2}$ This procedure, which created an atrial septal defect and thus allowed intra-atrial mixing of the pulmonary and systemic circulations, was the first to permit survival of neonates with TGA and intact ventricular septum (IVS).

In the mid 1950 s, early attempts at arterial switch operations failed. This failure was mainly due to difficulties with coronary transfer in small children. ${ }^{3-5}$ Therefore patients with TGA and IVS or with TGA and ventricular septal defect (VSD) were treated by means of an atrial switch op-

From the Departments of Cardiovascular Surgery ${ }^{\mathrm{a}}$ and Pediatric Cardiology and Congenital Heart Disease, ${ }^{\mathrm{b}}$ German Heart Center Munich, and the Institute of Medical Statistics and Epidemiology, ${ }^{\mathrm{c}}$ Technical University Munich, Munich, Germany.

Read at the Eighty-eighth Annual Meeting of The American Association for Thoracic Surgery, San Diego, Calif, May 10-14, 2008.

Received for publication April 24, 2008; revisions received July 22, 2008; accepted for publication Sept 12, 2008.

Address for reprints: Jürgen Hörer, MD, Lazarettstrasse 36, D-80636 Munich, Germany (E-mail: hoerer@dhm.mhn.de).

J Thorac Cardiovasc Surg 2009;137:347-54

$0022-5223 / \$ 36.00$

Copyright (c) 2009 by The American Association for Thoracic Surgery

doi:10.1016/j.jtcvs.2008.09.015 eration, such as the Senning operation ${ }^{6}$ (since 1957) or the Mustard operation $^{7}$ (since 1963). For more than 2 decades, these atrial switch operations were the treatment of choice for patients with TGA, with or without VSD.

In 1975 , Jatene and colleagues ${ }^{8}$ reported the first successful arterial switch operation. Despite the initially higher early mortality of the arterial switch relative to atrial switch operations, ${ }^{9}$ the move in surgical strategy from the atrial switch toward the arterial switch operation was mainly completed by the early 1990s. Concerns about the function of the systemic right ventricle in the long term after any atrial baffle procedure spurred this change in operative strategy. In addition, an increasing number of complications of those newly constructed venous pathways was observed. ${ }^{10}$

Because patients who have undergone arterial switch operations have now reached follow-up intervals as long as 30 years, it now seems reasonable to compare the long-term outcomes of patients after different types of repair for TGA. We therefore sought to determine the outcomes in terms of early and late survivals and freedom from reoperation for 929 patients treated for TGA at a single center.

\section{MATERIALS AND METHODS \\ Patients}

All patients who had undergone correction of TGA by means of an atrial or arterial switch operation between 1974 and 2006 were included in 


\section{Abbreviations and Acronyms \\ IVS = intact ventricular septum \\ LVOTO $=$ left ventricular outflow tract obstruction \\ NYHA $=$ New York Heart Association \\ TGA $=$ transposition of the great arteries \\ VSD $=$ ventricular septal defect}

a follow-up study. The study included 929 patients (Table 1). The Mustard operation was performed in 88 cases from 1974 until 1982, the Senning operation was performed in 329 cases from 1977 until 1993 (except for 3 patients), and the arterial switch operation was performed from 1983 onward (Figure 1). The surgical techniques are described elsewhere. ${ }^{11,12}$

This study was approved by the ethics committee of the Technical University Munich (1638/06). Individual consent for the study was obtained from each patient or the parents.

\section{Data Collection}

All data were collected from medical records and from follow-up examinations at the outpatient facilities. Records were retrospectively reviewed for demographic, morphologic, clinical, echocardiographic, and hemodynamic details. The congenital heart lesion was classified as simple TGA if the interventricular septum was intact and as TGA with VSD if there was a VSD. In cases of left ventricular outflow tract obstruction (LVOTO), the classifications were TGA with LVOTO versus TGA with VSD and LVOTO. Patients with a small, restrictive VSD that was not closed were also classified as having TGA with VSD.

Follow-up data were obtained by a written questionnaire or by telephone. The functional status was determined according to the New York Heart Association (NYHA) functional class. Patients or their parents were asked about the occurrence of cardiovascular events, such as arrhythmia, stroke, thrombosis, and reoperation, and also about previous cardiac catheterization, pacemaker implantation, hospital admissions, concomitant diseases, and medication. For patients who had died, their relatives and their general physicians were contacted to determine the cause of death.

Follow-up was conducted between 2003 and 2007. The numbers of patients who could not be contacted within this interval were 6 for the Mustard operation, 15 for the Senning operation, and 34 for the arterial switch operation. Follow-up of survivors of the initial hospitalization was $92.6 \%$ complete for the Mustard group, $95.2 \%$ for the Senning group, and $92.9 \%$ for the arterial switch group. Mean follow-up times were $22.6 \pm 8.1$ years for the Mustard, $18.2 \pm 5.7$ years for the Senning, and $9.5 \pm 5.7$ years for the arterial switch. Mean follow-up times of patients unavailable for final follow-up were $16.4 \pm 10.5$ years for the Mustard, $10.2 \pm 7.8$ years for the Senning, and $6.9 \pm 6.3$ years for the arterial switch. Mean follow-up time for the whole study population was $13.6 \pm 7.8$ years $(12,417$ patient-years).

During long-term follow-up, patients underwent routine examinations, including echocardiography and electrocardiography. Data from echocardiographic examinations from the outpatient clinics were evaluated according to written notes by one of the authors (JH). Systemic ventricular function was graded as normal or as mildly, moderately, or severely impaired. Insufficiency of the tricuspid valve for patients after an atrial switch operation and of the neoaortic valve for patients after an arterial switch were graded as none, mild, moderate, or severe. Twelve-lead resting and 24-hour ambulatory electrocardiography were used for evaluation of cardiac rhythm.

\section{Statistical Analysis}

Descriptive data for continuous variables are presented as mean $\pm \mathrm{SD}$, and categoric variables are presented as relative frequencies. The Fisher exact test was performed to detect significant differences between groups. For comparison of continuous variables between two groups, the $t$ test was used (2-tailed tests were used for all analyses). The probability of freedom from events was estimated according to the Kaplan-Meier method. The time of the Senning, Mustard, or arterial switch operation was designated as time zero. Freedom-from-event curves were compared with the log-rank test. Hazard ratios were estimated according to the Cox proportional model. Multivariate analyses were performed by means of a logistic regression model for the end point of in-hospital mortality and by means of a Cox proportional hazard model for the end points of late mortality and reoperation. Variables with $P$ values less than .1 in univariate analysis were entered into the multivariate models. Patients were assigned to 3 groups according to when surgery was performed $(<1985,1985-1995$, and $>1995)$. Analyses were performed with SPSS 16.0 for Windows (SPSS Inc, Chicago, Ill).

\section{RESULTS \\ Perioperative Data}

Patients who underwent the atrial type of repair significantly more often had LVOTO $(P<.001)$ and significantly

TABLE 1. Perioperative variables of 929 patients with transposition of the great arteries who underwent the Mustard, Senning, or arterial switch operation

\begin{tabular}{|c|c|c|c|c|}
\hline \multirow[b]{2}{*}{ Characteristic } & \multicolumn{2}{|c|}{ Atrial switch } & \multirow[b]{2}{*}{ Arterial switch $(\mathrm{n}=512)$} & \multirow[b]{2}{*}{$P$ value* } \\
\hline & Mustard $(\mathbf{n}=\mathbf{8 8})$ & Senning $(n=329)$ & & \\
\hline TGA with IVS (No.) & $44(50 \%)$ & $221(64.1 \%)$ & $317(61.9 \%)$ & .633 \\
\hline TGA with VSD (No.) & $31(35.2 \%)$ & $71(21.6 \%)$ & $186(36.3 \%)$ & $<.001$ \\
\hline TGA with LVOTO (No.) & $7(8.0 \%)$ & $15(4.6 \%)$ & $1(0.2 \%)$ & $<.001$ \\
\hline TGA with VSD and LVOTO (No.) & $6(6.8 \%)$ & $22(6.7 \%)$ & $8(1.6 \%)$ & $<.001$ \\
\hline VSD (No.) & $37(42.4 \%)$ & $93(28.3 \%)$ & $194(37.9 \%)$ & .038 \\
\hline LVOTO (No.) & $13(14.8 \%)$ & $37(11.2 \%)$ & $9(1.8 \%)$ & $<.001$ \\
\hline Palliative operation (No.) & $32(36.4 \%)$ & $25(7.6 \%)$ & $67(31.6 \%)$ & .846 \\
\hline Balloon atrial septostomy (No.) & $75(85.2 \%)$ & $307(93.3 \%)$ & $354(69.1 \%)$ & $<.001$ \\
\hline Age at correction $(y$, mean $\pm S D)$ & $2.7 \pm 2.4$ & $0.8 \pm 1.3$ & $0.2 \pm 0.9$ & $<.001$ \\
\hline Weight at correction $(\mathrm{kg}$, mean $\pm \mathrm{SD})$ & $11.3 \pm 5.3$ & $6.5 \pm 3.1$ & $4.0 \pm 3.1$ & $<.001$ \\
\hline In-hospital mortality (No.) & $7(8.0 \%)$ & $15(4.6 \%)$ & $33(6.4 \%)$ & .487 \\
\hline
\end{tabular}

$T G A$, Transposition of the great arteries; IVS, intact ventricular septum; $V S D$, ventricular septal defect; $L V O T O$, left ventricular outflow tract obstruction. *Atrial switch (both Mustard and Senning operations) versus arterial switch. 


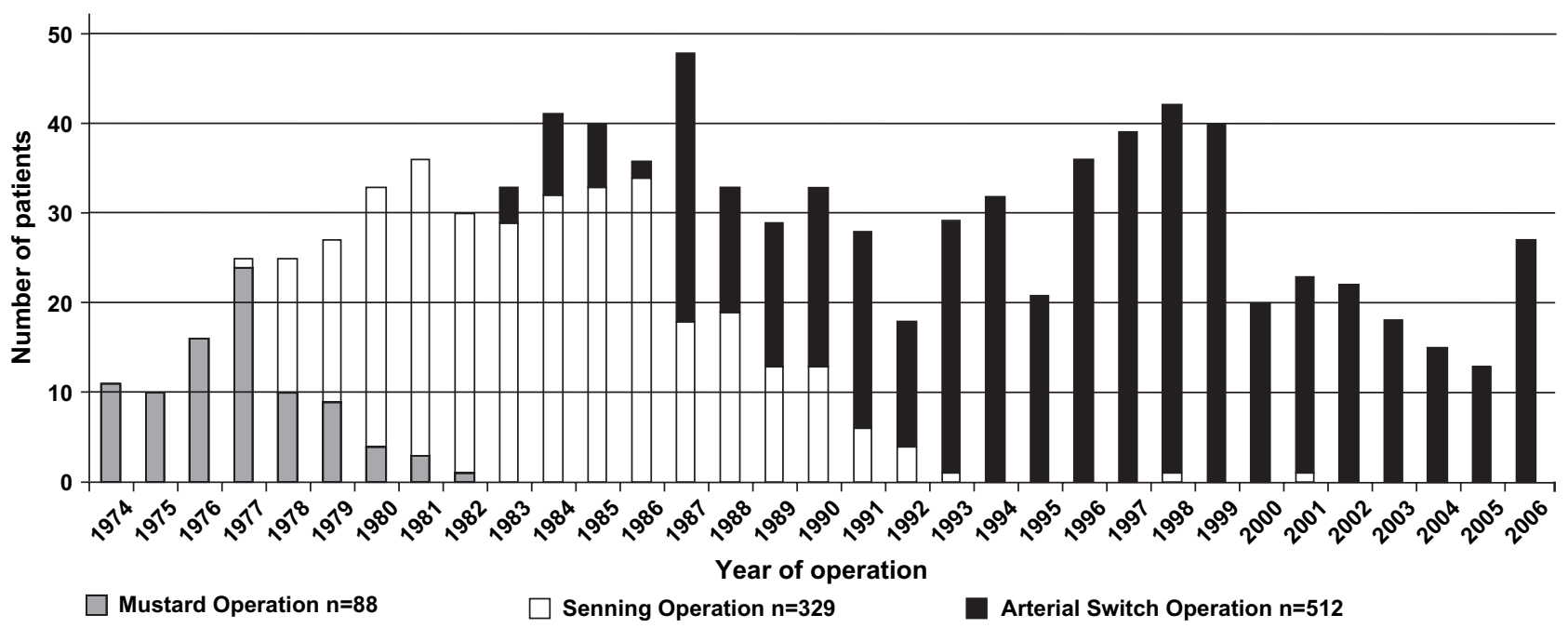

FIGURE 1. Number of operations stratified by type of operation and year between 1974 and 2006.

less often had VSD $(P=.038)$ than did patients who underwent the arterial type of repair. Patients who underwent the atrial type of repair significantly more often underwent balloon atrial septostomy $(P<.001)$ than did patients who underwent the arterial type of repair, and they were significantly older at the time of correction $(P<.001)$. Inhospital mortalities were $8.0 \%$ for the Mustard operation, $4.6 \%$ for the Senning operation, and $6.4 \%$ for the arterial switch operation. Among morphology, previous operations, age, and type of correction, presence of a VSD (hazard ratio $3.3, P<.001)$ was the only risk factor for in-hospital mortality in multivariate analysis (Table 2). Between 1983 and 1993, there was a change in surgical strategy from the Senning operation $(n=202)$ to the arterial switch operation $(\mathrm{n}=168)$. In that decade, significantly more patients who had TGA with VSD underwent an arterial switch operation $(P<.001)$. In-hospital mortality was approximately twice as high after the arterial switch operation $(4.8 \%)$ as after the Senning operation $(2.5 \%, P=.264)$.

\section{Late Death}

There were 20, 23, and 8 deaths after hospital discharge observed in the Mustard, Senning, and arterial switch groups, respectively. The highest survival at 20 years among those who survived hospitalization after the operation was observed after the arterial switch operation $(96.6 \% \pm$ $1.3 \%)$, followed by the Senning operation $(92.6 \% \pm$ $1.5 \%)$ and the Mustard operation $(82.4 \% \pm 4.3 \%)$. Survivals were significantly different between all pairs of groups (Figure 2). Among morphology, previous operations, time correction, age, and type of correction, the diagnosis of TGA with VSD (hazard ratio 3.1, $P<.001$ ), the diagnosis of TGA with VSD and LVOTO (hazard ratio 3.0, $P=.029$ ), and the Mustard operation (hazard ratio $2.1, P=.011)$ emerged as risk factors for death after hospital discharge, and the arterial switch operation emerged as a protective factor (hazard ratio $0.3, P=.010$; Table 3 ).

\section{Overall Survival}

There was a crossover of the survival curves after atrial switch and arterial switch operations at 9 postoperative months $(93.3 \% \pm 1.2 \%$ vs $93.3 \% \pm 1.1 \%)$. In the early postoperative phase, the atrial switch was superior to the arterial switch operation, whereas from 9 months onward the arterial switch was superior. Overall survivals at 10 and 20 years were $89.1 \% \pm 1.5 \%$ and $85.4 \% \pm 1.8 \%$, respectively, after atrial repairs and $92.2 \% \pm 1.3 \%$ and $90.4 \% \pm 1.6 \%$, respectively, after arterial repair. The difference in long-term survival, however, was not statistically significant $(P=.129)$.

\section{Late Reoperations}

Reoperations after hospital discharge were required in 30 Mustard, 33 Senning, and 52 arterial switch patients.

TABLE 2. Significant risk factors for death during hospitalization among 929 patients with transposition of the great arteries who underwent the Mustard, Senning, or arterial switch operation

\begin{tabular}{|c|c|c|c|}
\hline \multirow[b]{2}{*}{ Risk factor } & \multirow[b]{2}{*}{$\begin{array}{c}\text { Univariate } \\
\text { analysis } \boldsymbol{P} \text { value* }\end{array}$} & \multicolumn{2}{|c|}{ Multivariate analysis } \\
\hline & & $\begin{array}{c}\text { Hazard } \\
\text { rate }(95 \% \mathbf{C I})\end{array}$ & $\begin{array}{c}P \\
\text { value* }\end{array}$ \\
\hline Complex TGA & $<.001$ & & \\
\hline TGA with VSD & $<.001$ & & \\
\hline VSD & $<.001$ & $3.3(1.9-5.7)$ & $<.001$ \\
\hline Palliative operation & .038 & & \\
\hline \multicolumn{4}{|l|}{ TGA with VSD } \\
\hline Mustard operation & .008 & & \\
\hline Senning operation & .062 & & \\
\hline Arterial switch operation & .054 & & \\
\hline
\end{tabular}

$C I$, Confidence interval; $T G A$, transposition of the great arteries; $V S D$, ventricular septal defect. *Level of significant difference between groups of dichotomous variables listed in first column. 


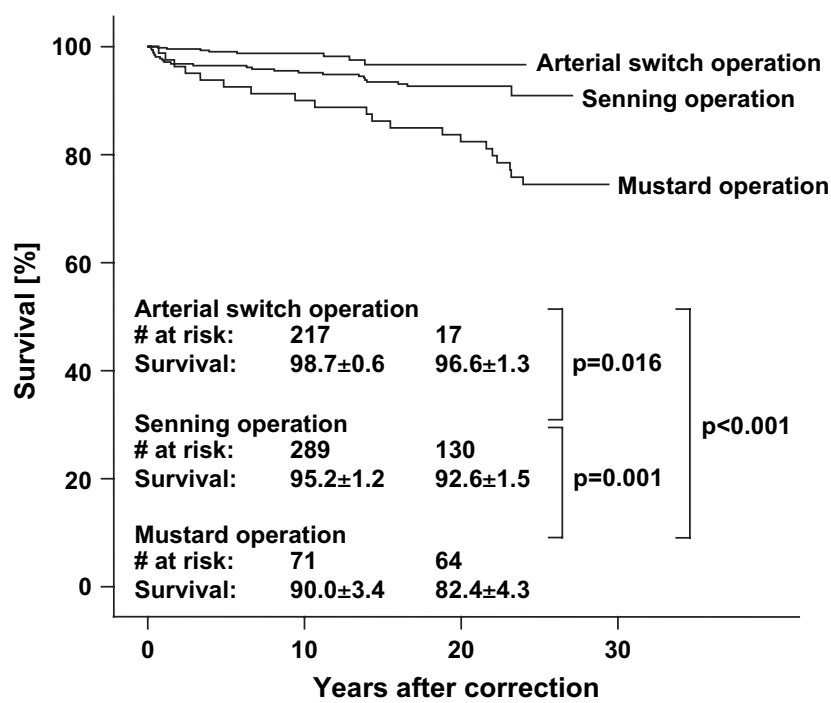

FIGURE 2. Estimated survival among survivors of initial hospitalization after correction stratified by type of operation.

Frequently, several procedures had to be performed during a single reoperative event, resulting in 67,66 , and 91 procedures performed in 37, 38, and 69 reoperations in the Mustard, Senning, and arterial switch groups, respectively (Table 4). The procedures most frequently performed in both atrial repair groups were relief of baffle stenosis, closure of baffle leaks, and procedures for systemic right ventricular dysfunction (arterial switch and Senning takedown, banding without conversion, tricuspid valve repair, cardiac transplantation). The most frequent procedures performed in the arterial switch group were relief of stenosis in the right ventricular outflow tract (including enlargement of pulmonary artery stenosis), relief of stenosis in the left ventricular outflow tract, and neoaortic valve replacement. The highest freedom from reoperation at 20 years was observed after the Senning operation $(88.7 \% \pm 1.9 \%)$, followed by the arterial switch operation $(75.0 \% \pm 6.4 \%)$ and the Mustard operation $(70.6 \% \pm 5.4 \%)$ (Figure 3). Among morphology, previous operations, timing of correction, age, and type of correction, presence of a complex transposition (hazard ratio 2.1, $P<$ .001 ), previous palliative operation (hazard ratio $1.8, P=$ .016 ), surgery between 1985 and 1995 (hazard ratio 2.6, $P=.002$ ), surgery after 1995 (hazard ratio $3.5, P<.001$ ), and the Mustard operation (hazard ratio 3.3, $P<.001$ ) emerged as risk factors for reoperation (Table 5).

\section{Cardiac Function During Long-Term Follow-up}

The function of the subaortic ventricle was at least moderately impaired in 36 patients after an atrial switch operation $(9.1 \%$ of those surviving initial hospitalization) and in 2 patients after an arterial switch operation $(0.4 \%$ of those surviving initial hospitalization). Sixty-one patients who underwent atrial switch operations showed at least mild tricuspid regurgitation after $(15.4 \%$ of those surviving the initial hospitalization), and 35 patients who underwent arterial switch operations showed at least mild neoaortic regurgitation ( $7.3 \%$ of those surviving the initial hospitalization).

Rhythm disturbances. Pacemaker implantation was required after discharge from the hospital in 12, 22, and 12 patients in the Mustard, Senning, and arterial switch groups, respectively. Freedoms from pacemaker implantation at 20 years were $89.3 \% \pm 3.6 \%$ for the Mustard group, $94.4 \%$ $\pm 1.4 \%$ for the Senning group, and $92.0 \% \pm 4.1 \%$ for the arterial switch group. Differences between groups were not statistically significant. Presence of a VSD at the time

TABLE 3. Significant risk factors for late death among 874 survivors through hospitalization after the Mustard, Senning, or arterial switch operation

\begin{tabular}{|c|c|c|c|c|c|c|}
\hline \multirow[b]{2}{*}{ Risk factor } & \multicolumn{3}{|c|}{ Univariate analysis } & \multicolumn{3}{|c|}{ Multivariate analysis } \\
\hline & Hazard ratio & $95 \% \mathrm{CI}$ & $P$ value* & Hazard ratio & $95 \% \mathrm{CI}$ & $P$ value* \\
\hline Complex TGA & 2.9 & $1.7-5.2$ & $<.001$ & & & \\
\hline TGA with VSD & 2.5 & $1.4-4.3$ & .001 & 3.1 & $1.7-5.5$ & $<.001$ \\
\hline TGA with VSD and LVOTO & 2.6 & $1.0-6.6$ & .042 & 3.0 & $1.1-7.9$ & .029 \\
\hline VSD & 3.0 & $1.7-5.2$ & $<.001$ & & & \\
\hline Palliative operation & 3.2 & $1.8-5.7$ & $<.001$ & & & \\
\hline \multicolumn{7}{|l|}{ Surgical period } \\
\hline 1985-1995 & 0.6 & $0.3-1.0$ & .066 & & & \\
\hline$>1995$ & 0.1 & $0.0-0.6$ & .014 & & & \\
\hline \multicolumn{7}{|l|}{ TGA with VSD } \\
\hline Mustard operation & 4.2 & $2.0-9.0$ & $<.001$ & & & \\
\hline Senning operation & 2.3 & $1.1-4.8$ & .021 & & & \\
\hline Mustard operation & 3.6 & $2.0-6.5$ & $<.001$ & 2.3 & $1.2-4.2$ & .011 \\
\hline Arterial switch operation & 0.3 & $0.1-0.6$ & .002 & 0.3 & $0.1-0.8$ & .010 \\
\hline Age at operation $>30 \mathrm{~d}$ & 3.1 & $1.4-6.7$ & .005 & & & \\
\hline
\end{tabular}

$C I$, Confidence interval; TGA, transposition of the great arteries; VSD, ventricular septal defect; $L V O T O$, left ventricular outflow tract obstruction. *Level of significance between the groups of dichotomous variables listed in the first column, except for the variables of surgical period 1985-1995 and surgical period >1995, for which reference is surgical period $<1985$. 
TABLE 4. Reoperations among 874 survivors through hospitalization after the Mustard, Senning, or arterial switch operation

\begin{tabular}{|c|c|c|c|}
\hline Procedure & Mustard & Senning & $\begin{array}{l}\text { Arterial } \\
\text { switch }\end{array}$ \\
\hline \multicolumn{4}{|l|}{ All reoperations } \\
\hline No. of reoperations & 37 & 38 & 69 \\
\hline No. of patients & 30 & 33 & 52 \\
\hline Closure of baffle leak & $7(18.9 \%)$ & $11(28.9 \%)$ & 0 \\
\hline $\begin{array}{l}\text { Enlargement of systemic } \\
\text { venous tunnel }\end{array}$ & $24(64.9 \%)$ & $10(26.3 \%)$ & 0 \\
\hline $\begin{array}{l}\text { Enlargement of pulmonary } \\
\text { venous tunnel }\end{array}$ & $18(48.6 \%)$ & $8(21.1 \%)$ & 0 \\
\hline $\begin{array}{l}\text { Enlargement of subvalvular } \\
\text { pulmonary stenosis }\end{array}$ & 0 & 0 & $10(14.5 \%)$ \\
\hline $\begin{array}{l}\text { Enlargement of valvular } \\
\text { pulmonary stenosis }\end{array}$ & $1(2.7 \%)$ & $2(5.3 \%)$ & $5(7.2 \%)$ \\
\hline $\begin{array}{l}\text { Enlargement of supravalvular } \\
\text { pulmonary stenosis }\end{array}$ & 0 & 0 & $16(23.2 \%)$ \\
\hline $\begin{array}{l}\text { Enlargement of pulmonary } \\
\text { arterial stenosis }\end{array}$ & 0 & 0 & $9(13.0 \%)$ \\
\hline $\begin{array}{l}\text { Enlargement of left } \\
\text { ventricular outflow tract } \\
\text { and aortic arch }\end{array}$ & $3(8.1 \%)$ & $13(34.2 \%)$ & $19(27.5 \%)$ \\
\hline Aortic valve replacement & 0 & $1(2.6 \%)$ & $11(15.9 \%)$ \\
\hline $\begin{array}{l}\text { Banding or debanding } \\
\text { of pulmonary artery }\end{array}$ & $2(5.4 \%)$ & $7(18.4 \%)$ & $3(4.3 \%)$ \\
\hline $\begin{array}{l}\text { Arterial switch } \\
\text { and atrial redirection }\end{array}$ & 0 & $5(13.2 \%)$ & 0 \\
\hline Procedure of tricuspid valve & $5(13.5 \%)$ & $4(10.5 \%)$ & $4(5.8 \%)$ \\
\hline $\begin{array}{l}\text { Closure of residual } \\
\text { ventricular septal defect }\end{array}$ & $5(13.5 \%)$ & $3(7.9 \%)$ & $9(13.0 \%)$ \\
\hline Other & $2(5.4 \%)$ & $2(5.3 \%)$ & $5(7.2 \%)$ \\
\hline
\end{tabular}

Percentages refer to percentage of total number of operations in group.

of repair emerged as a risk factor for shorter time to pacemaker implantation in multivariate analysis (hazard ratio $2.4,95 \%$ confidence interval $1.2-4.6, P=.012$ ).

Functional status. Information concerning the functional status at the time of final follow-up could be obtained for 789 patients (95.9\% of long-term survivors). Accordingly, $47.9 \%$ of the patients in the Senning group could be assigned to NYHA functional class I. The same percentage of patients $(47.9 \%)$ could be assigned to NYHA functional class II, with $4.1 \%$ assigned to NYHA functional class III. In the Mustard group, $44.6 \%, 48.2 \%$, and $7.1 \%$ of the patients were assigned to NYHA functional classes I, II, and III, respectively. Almost all patients in the arterial switch group could be assigned to NYHA functional class I $(98.3 \%)$, with only $1.7 \%$ in NYHA functional class II.

\section{DISCUSSION}

From the historical point of view, the atrial switch operation preceded the arterial switch operation. Despite the age-related incidence of baffle stenosis, ${ }^{13}$ however, the

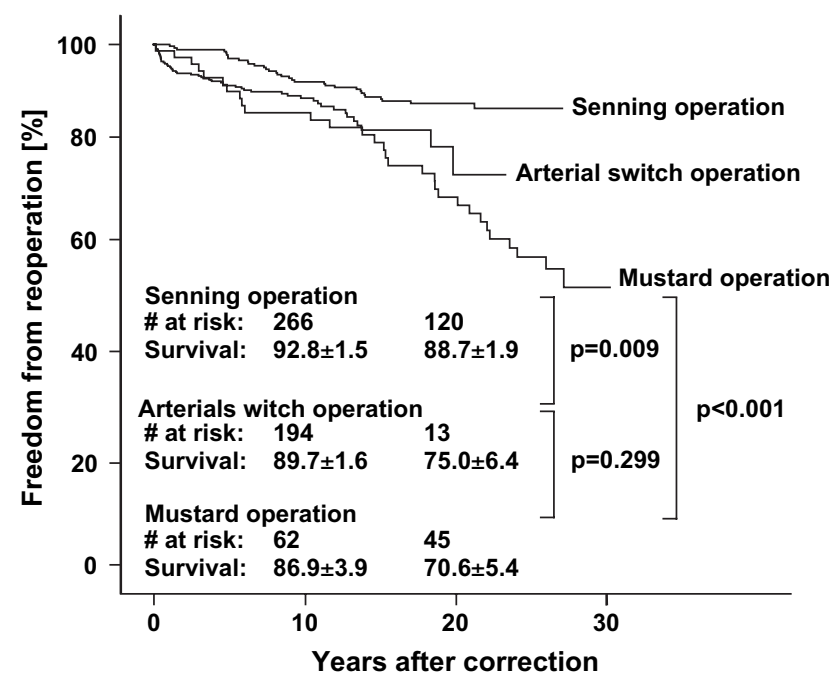

FIGURE 3. Estimated freedom from reoperation among survivors of initial hospitalization after correction stratified by type of operation.

main disadvantage of the atrial switch operation is the incorporation of the right ventricle into the systemic circulation. With time, increasing numbers of patients with diminished exercise tolerance $^{14}$ and impaired systemic right ventricular function ${ }^{15}$ have been reported. The arterial switch operation was introduced because of its potential advantage in incorporating the left ventricle into the systemic circulation. Although the first successful arterial switch operation was performed as early as 1975 by Jatene and colleagues, ${ }^{16}$ it was not until the 1990s that the transition from the atrial switch operation to the arterial switch took place. The main reason for this long transition was the concern with abandoning a well-established procedure with an early mortality below $5 \%{ }^{17-19}$ in favor of a demanding procedure with unknown early mortality.

In fact, during the transition from the atrial to the arterial repair, early mortality of the arterial switch operation was reported to be higher than that of the atrial switch operation. In a series of 829 patients treated for TGA between 1985 and 1989, Williams and coworkers ${ }^{9}$ reported an early mortality of $14.9 \%$ after the arterial switch operation, compared with 3.6\% after the Mustard operation. In our study population, early mortalities during the transition from the Senning to the arterial switch were $2.5 \%$ and $4.8 \%$, respectively. This difference, however, was not statistically significant. In addition, in our study population, type of repair had no impact in multivariate analysis on early mortality calculated for the whole study period. Presence of a VSD was the only risk factor for in-hospital mortality in multivariate analysis. In our analysis early mortality of patients undergoing repair of TGA was determined by the presence of a VSD, not by the type of correction or by the surgical period. The higher early mortality among patients after arterial switch operations during the transitional era thus may be explained by 
TABLE 5. Significant risk factors for reoperations among 874 survivors through hospitalization after the Mustard, Senning, or arterial switch operation

\begin{tabular}{|c|c|c|c|c|c|c|}
\hline \multirow[b]{2}{*}{ Risk factor } & \multicolumn{3}{|c|}{ Univariate analysis } & \multicolumn{3}{|c|}{ Multivariate analysis } \\
\hline & Hazard ratio & $95 \%$ CI & $P$ value* & Hazard ratio & $95 \%$ CI & $P$ value* \\
\hline Complex TGA & 2.6 & $1.8-3.8$ & $<.001$ & 2.1 & $1.4-3.1$ & $<.001$ \\
\hline TGA with VSD & 2.3 & $1.6-3.3$ & $<.001$ & & & \\
\hline TGA with VSD and LVOTO & 1.9 & $0.9-3.8$ & .091 & & & \\
\hline VSD & 2.5 & $1.7-3.6$ & $<.001$ & & & \\
\hline LVOTO & 1.8 & $1.0-3.1$ & .049 & & & \\
\hline Palliative operation & 2.8 & $1.8-5.7$ & $<.001$ & 1.8 & $1.1-2.8$ & 016 \\
\hline \multicolumn{7}{|l|}{ Surgical period } \\
\hline 1985-1995 & 1.3 & $0.8-2.1$ & .230 & 2.6 & $1.4-4.6$ & .002 \\
\hline$>1995$ & 1.7 & $1.0-3.0$ & .072 & 3.5 & $1.8-7.1$ & $<.001$ \\
\hline Mustard operation & 2.2 & $1.4-3.4$ & $<.001$ & 3.2 & $1.8-6.1$ & $<.001$ \\
\hline Senning operation & 0.4 & $0.3-0.6$ & $<.001$ & & & \\
\hline Arterial switch operation & 1.4 & $1.0-2.1$ & .080 & & & \\
\hline \multicolumn{7}{|l|}{ TGA with VSD } \\
\hline Mustard operation & 2.3 & $1.2-4.4$ & .014 & & & \\
\hline Arterial switch operation & 2.4 & $1.6-3.7$ & $<.001$ & & & \\
\hline
\end{tabular}

$C I$, Confidence interval; TGA, transposition of the great arteries; $V S D$, ventricular septal defect; $L V O T O$, left ventricular outflow tract obstruction. *Level of significance between groups of dichotomous variables listed in first column, except for the variables of surgical period 1985-1995 and surgical period $>1995$, for which reference is surgical period $<1985$.

the fact that significantly more patients who underwent arterial switch operations had TGA with VSD.

It is of major interest whether the arterial switch operation has fulfilled our expectations with regard to improvements in long-term functional outcome and mortality. Losay and associates ${ }^{20}$ reported a survival of $88 \%$ at 15 years after an arterial switch operation in a group of 1095 survivors of initial hospitalization, with no late deaths beyond 5 years after initial repair. Other authors have also reported low incidences of late death after the arterial switch operation. ${ }^{9,21}$ In contrast, survival after atrial switch operations has been reported to be as low as $77 \%$ at 15 years, ${ }^{22}$ although reports range as high as $94 \%$ at 15 years..$^{9,10,22,23}$

Comparisons between the atrial and the arterial types of repair with regard to mortality in the long-term are biased by the different follow-up intervals for the 2 groups of patients. To overcome this error, Williams and coworkers ${ }^{9}$ performed a study that included only patients operated on during the transition from the atrial switch to the arterial switch operation (between 1985 and 1989). The methodologic problem of that study, however, consisted in comparing the well-established surgical technique of atrial switch with the newly introduced technique of arterial switch. The effect was the previously mentioned difference in early mortality $(14.9 \%$ after arterial switch vs $3.6 \%$ after atrial switch). We therefore included all patients, irrespective of the time of initial repair. To reveal the potential effect of the time of repair, the surgical period $(<1985,1985-1995$, and $>1995)$ was included as a covariable in the multivariate model. The surgical period was found to have no statistical influence on late mortality.

Because of the higher early mortality with the arterial repair relative to the atrial repair and the higher late mortality with the atrial repair relative to the arterial repair, there is a crossover of the survival curves in favor of the arterial repair. In the study reported by Williams and coworkers, ${ }^{9}$ this crossover was observed at 17 years after the initial repair. In our study population, this crossover took place within the first year after repair. This earlier crossover was due to the lower early mortality of the arterial switch operation in our cohort than the cohort studied by Williams and coworkers. ${ }^{9}$ Thus with regard to overall survival, there was a benefit of the arterial switch operation as soon as 1 year after initial repair. This finding was confirmed by multivariate testing in our study population. The type of repair had no statistically significant influence on early mortality, whereas the hazard for late death among patients after an arterial repair was less than a third that among patients after an atrial repair. In this context, it is noteworthy that preoperative mortality among neonates scheduled for an atrial repair was reported to be higher than that among patients scheduled for an arterial repair $(4.7 \% \text { vs } 2.5 \%)^{9}$ as a result of the longer time of palliation and older age of the children at the time of atrial switch repair. Thus the benefit of the arterial switch with respect to overall mortality from birth may even be more evident.

According to many previously published series, ${ }^{20,22-24}$ survival in the long term was found to be determined by the complexity of the heart defect. Patients who had TGA with VSD, or TGA with VSD and LVOTO had a 3-fold greater risk for late death than did patients who had TGA with IVS. Finally, survival in our study population was higher after the Senning operation than after the Mustard operation. Interestingly, this finding is in line with other reports from Europe ${ }^{22}$ whereas the experiences in North America seem to be contrary. ${ }^{24}$ 
Freedom from reoperation has been reported to vary between $60 \%$ and $90 \% 20$ years after an atrial switch operation. $9,10,22$ The main indications for reoperation were stenoses and leaks of the venous pathways, which seem to be more frequent after the Mustard operation than after the Senning operation. ${ }^{10,22}$ As expected, with the transition from the atrial repair to the arterial repair, the main location of complications requiring reoperation shifted from the inflow to the outflow of the ventricles. Stenoses of the pulmonary arteries therefore accounted for most of the more than 100 reoperations necessary in the large study population reported on by Losay and associates. ${ }^{20}$ Accordingly, freedom from reoperation at 15 years was $82 \%$ in their study population.

These findings could be confirmed in our study. The main indications for reoperation after the arterial switch operation were stenoses of the right ventricular outflow tract and the pulmonary arteries, which were corrected in $46 \%$ of the 52 patients who required reoperation. The main indications for reoperation after the atrial switch operations were complications of the venous pathway, which were corrected in $63 \%$ of the 63 patients who required reoperation. In our study population, freedoms from reoperation at 20 years were $75.0 \% \pm 6.4 \%$ after arterial switch operations and $84.5 \% \pm 2.0 \%$ after atrial switch operations. This difference, however, was not statistically significant, although freedom from reoperation after the Senning operation was significantly higher than that after the arterial switch operation. In our experience, there was no improvement with regard to freedom from reoperation after the introduction of the arterial switch operation.

Functional status appeared to be superior after the arterial switch relative to the atrial switch operations. According to different studies, $66 \%$ to $93 \%$ of the patients after atrial switch are in NYHA functional class I, ${ }^{10,23,25}$ versus almost all patients after arterial switch, ${ }^{26}$ a finding confirmed in our investigation $(98 \%$ in NYHA functional class I after arterial switch). These subjective findings in functional status were reflected in the objective measurements of the cardiac function. At echocardiographic examination during follow-up, only $0.4 \%$ of the patients after arterial switch showed at least moderately impaired left ventricular function, whereas $9.1 \%$ of the patients after atrial switch showed at least moderately impaired right ventricular function. The significant differences in follow-up time between the atrial and the arterial types of repair, however, must be kept in mind.

\section{Study Limitations}

This was a retrospective follow-up study covering a long period of patient inclusion. Changes in preoperative, operative, and postoperative management may have affected the outcome parameters in ways not covered by our analysis. The comparability of the echocardiographic findings and
NYHA functional status at the time of final follow-up between the repair technique groups is also limited by the differences in follow-up time.

\section{CONCLUSIONS}

The change from the atrial to the arterial switch led to improved long-term survival and improved functional status but not to lower incidence of reoperation. Both survival and freedom from reoperation are determined by the presence of a VSD at the time of correction.

\section{References}

1. Talner CN. Report of the New England Regional Infant Cardiac Program, by Donald C. Fyler, MD, Pediatrics, 1980;65(suppl):375-461. Pediatrics. 1998; 102(1 Pt 2):258-9.

2. Blalock A, Hanlon CR. The surgical treatment of complete transposition of the aorta and the pulmonary artery. Surg Gynecol Obstet. 1950;90:1-15.

3. Bailey CP, Cookson BA, Downing DF, Neptune WB. Cardiac surgery under hypothermia. J Thorac Surg. 1954;27:73-95.

4. Kay EB, Cross FS. Surgical treatment of transposition of the great vessels. Surgery. 1955;38:712-6.

5. Mustard. A surgical approach to transposition of the great vessels with extracorporeal circuit. Surgery. 1954;36:39-51

6. Senning A. Surgical correction of transposition of the great vessels. Surgery. 1959;45:966-80.

7. Mustard WT. Successful two-stage correction of the transposition of the great vessels. Surgery. 1963;55:469-72.

8. Jatene AD, Fontes VF, Paulista PP, de Souza LC, Neger F, Galantier M, et al. Successful anatomic correction of transposition of the great vessels. A preliminary report. Arq Bras Cardiol. 1975;28:461-4.

9. Williams WG, McCrindle BW, Ashburn DA, Jonas RA, Mavroudis C, Blackstone EH. Outcomes of 829 neonates with complete transposition of the great arteries 12-17 years after repair. Eur J Cardiothorac Surg. 2003; 24:1-10.

10. Oechslin E, Jenni R. 40 years after the first atrial switch procedure in patients with transposition of the great arteries: long-term results in Toronto and Zurich. Thorac Cardiovasc Surg. 2000;48:233-7.

11. Lange R, Horer J, Kostolny M, Cleuziou J, Vogt M, Busch R, et al. Presence of a ventricular septal defect and the Mustard operation are risk factors for late mortality after the atrial switch operation: thirty years of follow-up in 417 patients at a single center. Circulation. 2006;114:1905-13.

12. Haas F, Wottke M, Poppert H, Meisner H. Long-term survival and functional follow-up in patients after the arterial switch operation. Ann Thorac Surg. 1999;68: 1692-7.

13. Cobanoglu A, Abbruzzese PA, Freimanis I, Garcia CE, Grunkemeier G Starr A. Pericardial baffle complications following the Mustard operation. Age-related incidence and ease of management. J Thorac Cardiovasc Surg. 1984;87:371-8.

14. Mathews RA, Fricker FJ, Beerman LB, Stephenson RJ, Fischer DR, Neches WH, et al. Exercise studies after the Mustard operation in transposition of the great arteries. Am J Cardiol. 1983;51:1526-9.

15. Murphy JH, Barlai-Kovach MM, Mathews RA, Beerman LB, Park SC Neches WH, et al. Rest and exercise right and left ventricular function late after the Mustard operation: assessment by radionuclide ventriculography. Am J Cardiol. 1983;51:1520-6.

16. Jatene AD, Fontes VF, Paulista PP, Souza LC, Neger F, Galantier M, et al. Anatomic correction of transposition of the great vessels. J Thorac Cardiovasc Surg 1976;72:364-70

17. Kirjavainen M, Happonen JM, Louhimo I. Late results of Senning operation. J Thorac Cardiovasc Surg. 1999;117:488-95.

18. Agnetti A, Carano N, Cavalli C, Tchana B, Bini M, Squarcia U, et al. Long-term outcome after Senning operation for transposition of the great arteries. Clin Cardiol. 2004;27:611-4.

19. Bender HW Jr, Stewart JR, Merrill WH, Hammon JW Jr, Graham TP Jr. Ten years' experience with the Senning operation for transposition of the great arteries: physiological results and late follow-up. Ann Thorac Surg. 1989;47:218-23. 
20. Losay J, Touchot A, Serraf A, Litvinova A, Lambert V, Piot JD, et al. Late outcome after arterial switch operation for transposition of the great arteries. $\mathrm{Circu}$ lation. 2001;104(12 Suppl 1):I121-6.

21. Hutter PA, Kreb DL, Mantel SF, Hitchcock JF, Meijboom EJ, Bennink GB. Twenty-five years' experience with the arterial switch operation. J Thorac Cardiovasc Surg. 2002;124:790-7.

22. Sarkar D, Bull C, Yates R, Wright D, Cullen S, Gewillig M, et al. Comparison of long-term outcomes of atrial repair of simple transposition with implications for a late arterial switch strategy. Circulation. 1999;100(19 Suppl):II176-81.

23. Moons P, Gewillig M, Sluysmans T, Verhaaren H, Viart P, Massin M, et al. Long term outcome up to 30 years after the Mustard or Senning operation: a nationwide multicentre study in Belgium. Heart. 2004;90:307-13.

24. Wells WJ, Blackstone E. Intermediate outcome after Mustard and Senning procedures: a study by the Congenital Heart Surgeons Society. Semin Thorac Cardiovasc Surg Pediatr Card Surg Annu. 2000;3:186-97.

25. Sasaki O, Hamada M, Hiasa G, Ogimoto A, Ohtsuka T, Suzuki M, et al. Congenitally corrected transposition of the great arteries in a 65-year-old woman. Jpn Heart J. 2001;42:645-9.

26. Prêtre R, Tamisier D, Bonhoeffer P, Mauriat P, Pouard P, Sidi D, et al. Results of the arterial switch operation in neonates with transposed great arteries. Lancet. 2001;357:1826-30

\section{Discussion}

Dr Winfield J. Wells (Los Angeles, Calif). First, congratulations. Doing a long-term follow-up study on more than 900 patients is a lot of work. I can't imagine how long this took. As I read the manuscript, it seemed to me that the most relevant information came from your analysis of the long-term outcomes of the arterial switch subgroup. The atrial switch results are interesting from a historical standpoint, but the arterial switch patients are of greatest interest. My questions are therefore limited to those in the arterial switch subgroup.

First, in your title you mention freedom from reoperation, but what about other reinterventions? I'm sure that the cardiologists in Germany must be performing percutaneous interventions, just as they are here in North America. How many of the patients in the arterial switch group had balloon or stent interventions, or something of that nature?

Dr Hörer. For the arterial switch group, I do not know the exact number, but so far not more than 10 patients have undergone reintervention. Our data are limited to reoperation, not reintervention.

Dr Wells. I bring this up because in the long-term follow-up study conducted by the Congenital Heart Surgeons Society, there were a significant number of reinterventions in addition to the reoperations, particularly in the arterial switch group.

Second, did you test for the occurrence of reoperation against time? In other words, if you looked at the group operated on early as opposed to late in the experience, was there a difference in the need for reoperation?

Dr Hörer. Yes, there was a difference. But we tested this only in the overall group, including all 913 patients. We found that a more recent operation was an independent risk factor for reoperation. The reason is that the patients who underwent the arterial switch operation were operated on within the last 15 years, as opposed to the patients who underwent the atrial switch operation mainly between 1975 and 1985. Patients who underwent the arterial switch operation underwent reoperation more frequently, mainly for pulmonary stenosis. I think that we have overcome this problem, in part, because now we use a trouser-shaped patch to reconstruct the pulmonary arteries. We have not seen those early pulmonary stenoses within the last 5 years of our experience with the arterial switch operation.

Dr Wells. I suggest that within the arterial switch group itself you test for year of operation to see whether the incidence of reoperation went down as the team gained greater experience with the procedure. Another thing that comes out in your data is that there were a fair number of late reoperations. If I recall your actuarial curve for freedom from reoperation, the freedom went from $87 \%$ down to around $70 \%$ between 10 years and 20 years. What were these late reoperations?

Dr Hörer. The late reoperations in the arterial switch group are related to neoaortic insufficiency. The rate of reoperation for neoaortic insufficiency, however, is still below 3\%. In the atrial switch group, we saw late reoperations in the Mustard group for baffle stenosis but mainly for systemic ventricular dysfunction. These operations included tricuspid valve repair, banding of the pulmonary artery, and conversion to the arterial switch operation.

Dr Wells. In the arterial switch group, among those with a late reoperation for neoaortic insufficiency was there a correlation with VSD? If so was the VSD repaired through the neoaortic valve in most cases?

Dr Hörer. There was no correlation in multivariate analysis. There were correlations in univariate analysis with LVOTO, VSD, previous banding, and the diagnosis of Taussig-Bing. There was, however, no correlation with presence of a VSD in multivariate analysis. VSD closure was not performed through the neoaortic valve. 